\title{
EDUCATION FOR SUSTAINABILITY THROUGH ACADEMIC FREEDOM
}

\author{
CECILIA O. EKWUEME, ESTHER E. EKON AND D. C. EZENWA-NEBIFE
}

(Received 10, November 2015; Revision Accepted 4, January 2016)

\begin{abstract}
Most challenging developments in Nigeria in recent times are the issues of poverty, human right, gender inequality, cultural diversity and education for all. These issues have eaten deep into the society that policy makers and stake-holders in education are worried and are in search for possible solutions. Past researches are of the opinion that education for sustainable development and academic freedom could assist in solving these ethical menaces. Education for sustainable development allows every human being to acquire knowledge, skills, attitudes and values necessary to shape a sustainable future to make judgments and choices in favor of sustainable lifestyle. In the same vein, academic freedom leads to the expansion and discovery of new ideas of knowledge, transmits and preserves culture developed in the learner's independent judgment of an environment free from external control and domination. Educational opportunities that Nigerian children would have enjoyed through Education For All to achieve sustainability and self reliance is lacking due to factors enumerated above. In this contribution, we reviewed issues that pertain to how Education For All can be sustained and their goals achieved so that every child in Nigeria could be given equal rights to read and write irrespective of his or her tribe, age, background and gender.
\end{abstract}

KEYWORDS Sustainability, Academic Freedom, Education, Gender, Opportunity.

\section{INTRODUCTION}

Education is seen or believed to be the activity of preserving, developing and transmitting the culture of people from one generation to another (Okno-Saye Orobite, 2005). It enables the people to develop the knowledge, values and skills to participate in decision making about them, individually, collectively and globally. This vision of development embraces environmental concern as well as issues such as the fight against poverty, human right, gender equality, cultural diversity and education for all. To this end, Education is a means through which sustainable development can be achieved.

Education for sustainable development allows every human being to acquire knowledge, skills, attitudes and values necessary to shape a sustainable future. According to Nayar (2013), sustainable development is a development that meets the needs of the present without compromising the ability of future generation to meet their own needs. Nayar (2013) further stressed that sustainable development promotes critical thinking and decision making in a collaborative manner. Education for sustainability could explore students and create opportunities for them to learn and examine how the resources they use affect the Earth. Education for sustainability includes learning about the environment, interacting with the environment to make choices and prevent harmful activities in the environment. Education for sustainable development fosters and strengthens the capacity of individuals to make judgments and choices in favor of sustainable life style. The

Cecilia O. Ekwueme, Department of Science Education, Faculty of Education, University of Calabar, Calabar, Cross River State, Nigeria.

Esther E. Ekon, Department of Science Education, Faculty of Education, University of Calabar, Calabar Cross River State, Nigeria.

D. C. Ezenwa-Nebife, Federal Government Girls' College, Calabar, Cross River State, Nigeria. 
strategy aims at ensuring that learners are equipped with the relevant knowledge, and the key dispositions, skills and values to motivate and empower them to become informed citizens.

Converse to the traditional way of teaching, Education for sustainable development means adopting a more holistic approach to education with the aim of creating a better world for this generation and for the future generations. Presently in Nigeria, sustainable development has been incorporated into school curriculum to create awareness on issues such as climate change, disaster risk reduction, biodiversity, poverty reduction and sustainable consumption. To create this awareness in the classroom, it requires participatory, activity- based, learnercentered teaching methods that could motivate and empower the learners to change their behaviors and take actions for sustainable development. The knowledge acquired could help the learners to be able to relate what they learn in the classroom to their real life activities and will increasingly be in a better position to take the lead in changing behaviors and adopting sustainable life styles. This means that if every child in Nigeria gains academic freedom to read and write irrespective of their tribe, age, background and gender, their lifestyles would be improved and sustained.

Freedom is a natural law for all men. It is a law which protects an individual right to access, explore, consider and express ideas and information as the basis for a self-governing, well- informed citizenry. Thus Academic Freedom can be seen as the integral component of a democratic society. Academic freedom leads to the expansion and discovery of new ideas of knowledge. It transmits and preserves culture developed in the learner's independent judgment in an environment free from external control and domination. Editors of Encyclopedia Britannica (2014) defines Academic Freedom as freedom of teachers and students to teach, study and pursue knowledge and research without unreasonable interference or unreasonable restrictions from law, institutional regulators or public pressure. Fourie (2008) posited that academic freedom encompasses the freedom to hold, receive and disseminate ideas without restriction.

Dictionary of Education, defines Academic Freedom in four ways:

- The first is that it is "the liberty to teach, study through the medium of research, and published opinions and findings without censorship through the State or any of its units of authority such as School Boards".

- The right of teachers, especially at higher/college levels to teach the truth as they see it without interference from the Lay Boards, Governmental Authority Pressure Groups.

- It is the Freedom of Speech of the Press, and of partitions in those fields of which one is especially competent.

- It is the right to interpret facts without censorship.

Furthermore, Academic Freedom can be defined as the freedom where Scholars should have freedom to teach or communicate ideas or facts without being targeted for repression, job loss or imprisonment. The Universal Declaration of Human right (2010) Article 19 states that "everyone has the right to freedom of opinion and expression, this right includes: freedom to hold opinions without interference and to seek, receive and impart information and ideas through any media and regardless of frontiers".

Education for sustainable development could be achieved through different strategies. These strategies includes: Education for All, Gender Equality, Cultural Diversity, among others.

Education for All (EFA) is a global movement led by UNESCO (United Nation Educational Scientific and Cultural Organization). The aim of that movement was to meet the learning needs of all children, youths and adults by the year 2015 . The group saw the need for all to be educated because education is very crucial for sustenance of meaningful life.

Education is seen as a right just like a right to have food or freedom of speech. It is seen as a passport to human development. It opens doors and expands opportunities and freedom. It contributes to fostering peace, democracy and economic growth of the citizenry. UNESCO was mandated to lead the movement and to coordinate the international efforts to achieve this goal. Since the mandate started, there had been several conferences held in several countries to deliberate on strategies to achieve this goal, such conferences includes:

- World Conference on Education for All (Jomtien Thailand, 1990)

- World Education Forum (Dakar, Senegal, 2000) 
At Senegal ten years later, the participants discovered that many countries were far from reaching the goal set out in 1990 in Thailand by the world conference on Education for All. The participants numbered up to 1100 drawn from all- over the world agreed on the Dakar framework for action re-affirming their commitment towards achieving the goal in 2015 and identified six key measurable Education goals that would help achieve this mandate. These goals are:

- Expand early childhood care and Education.

- Provide free and compulsory primary Education for All.

- Promote learning and life skills for young people and adults.

- Increase adult literacy by $50 \%$.

- Achieve gender parity by 2005 , gender equality by 2015.

- Improve the quality of Education.

In 2000, the World Government adopted the six EFA goals and the eight Millennium Development Goals (MDGs) which has been replaced with Sustainable Development Goals (SDG). The two set of goals are timely road maps for the world to follow. The ultimate aim of Education for All is sustainable development.

\section{The Millennium Development Goals (MDGs)} are:

- Eradicate extreme poverty and hunger.

- Achieve universal primary Education.

- Promote gender equality and empower women.

- Reduce child mortality.

- Improve maternal health.

- Combat HIV/Aids, malaria and other diseases.

- Ensure environmental sustainability.

- Develop a global partnership for development.

On the other hand, the Sustainable Development Goals includes liaising with the government and media for awareness, empower stakeholders by providing tools, resources and training to build multi-stakeholders' capacity to achieve their aims through engagement with UN, National Government and media (Sustainable Development, 2015).

To achieve all these, both genders must be exposed to quality education and be given equal opportunities in all areas of life.
Gender refers to the social roles, responsibilities and behaviors believed to belong to men and women. Gender equality through sustainable development means giving every child boy or girl, man or woman equal opportunity to obtain quality Education. Education and its acquisition as we all know are very crucial for the sustenance of meaningful life. For a healthy and equitable society, Education must be qualitatively provided to every citizen irrespective of the gender to ensure stability, freedom and wellbeing of members of the community. The purpose of Education is to change individual orientation and behavior for the better tomorrow. Promoting gender equality has become a globally recognized and an acceptable reality. Gender issues have also been identified as critical to the achievement of national development goals. The attainment of gender equality is seen as a catalyst through which sustainable development could be attained. Establishing a gender-friendly and gender-sensitive society that is devoid of all vestiges of discrimination and inequality is not only necessary for sustainable development efforts in Nigeria, but also a pragmatic approach to an appropriate policy formulation that could bring about national re-orientation among the citizenry. To achieve this aim, it is very necessary that the provision of education must be highly qualitative in order to produce a large number of learned scholars who could continuously enlarge the frontier of knowledge and therefore make life meaningful. Gender equality is the view that men and women should receive equal treatment, and should not be discriminated against based on gender. Gender equality is a means whereby women and men enjoy the same rights and opportunities across all sectors of the society including economic, participation and decision making. Gender equality is one of the UNESCO'S two global priorities with a commitment to promote equality between men and women across the organization's mandate since 2008. It is not only a fundamental human right, but a necessary foundation for the creation of sustainable and peaceful societies. And yet around the world, women still have less access to Education, to decent employment, and to basic resources and services. Despite progress towards gender parity in Education, 35 million girls of primary school age, and 37 million girls of lower secondary school age are out of school (UNESCO, 2013). Women voices are sometimes not heard in decision making or policy making processes. UNESCO also commits itself to 
ensure that the organization's contributions to sustainable development and peace have a positive and lasting impact on the achievement of women's empowerment and gender equality around the globe. To maintain a sustainable future, education for all, gender equality and cultural diversity must be given priority in Nigerian's Education system.

Culture implies the overall way of life for a group of individuals. Culture is the glue that binds people together, and enables them to adapt, survive and live together in harmony. It is the totality of people's way of life. Culture shapes the thinking of its people, influences behaviors and personality. Culture is a learned pattern of behavior. It is an integral part of every society, and creates a feeling of belonging and togetherness among the people of that society. Culture encompasses various aspects of communication, attitudes, beliefs, values, customs, norms, clothing styles, among others. Furthermore, culture means the complexity of solutions which the human community inherits, adopts or invents in order to meet the challenges of its natural and social environment (Gollnick and Chin, 2006).

Many researchers define culture differently. Tylor (2012) defined culture as the complex whole, which includes knowledge, belief, art, morals, law, customs and other capabilities and habits acquired by men as members of the society. Zimmermann (2015) defined culture as the characteristics and knowledge of a particular group of people, defined by everything from language, religion, social habits, music and arts. Carla (2014) defined culture as the shared pattern of behaviors and interactions, cognitive constructs and affective understanding that are learned through a process of socialization. Every society has different culture, which gives it an identity and uniqueness. In spite of the vast cultural diversity, there are certain elements of culture that are universal, such as use of jewelry, classifying people according to gender and age, among others.

We live in the world with an abundant array of diversity. Diversity is evident in people, the environment and all forms of life. Advancement in technology have made the world seem smaller and increased the interaction between people from different cultures. In other to educate the future generations of our society effectively, the education system must be focused on teaching all the students to communicate and interact with people from different background and with different abilities. However, it is also important to remember that all students' are culturally diverse regardless of their ethnicity, race or socio-economic status. Teachers must be aware of the diversity in their classrooms and how it may impact students' achievement. To maintain a country where social mobility and opportunity are viable, teachers must find ways to offer an excellent education to all students regardless of their background. Diversity is a fundamental aspect of our world and a defining characteristic of the field of special education. Cultural diversity means the variety of human societies or cultures in a specific region or in the world as a whole (Nicole and Miles, 2010). Cultural diversity encompasses the cultural differences that exist between people such as language, dress and tradition, the way societies organize themselves, their conceptions and the way they interact with the environment. This can be referred to as the different cultures and the respect for each other. Cultural diversity is important for sustainable development. The sustainability is crucial for the survival of human kind. The United Nation Millennium Declaration (2000) stressed that respect for Nation was one of the fundamental values for humanity. The Declaration stated that prudence must be shown in the management of all living species and natural resources in accordance with the precepts of sustainable development. Cultural diversity unites individuals, societies and peoples. Cultural diversity guarantees sustainability because it binds universal developmental goals to plausible and specific moral vision. For sustainability in education, different cultures in the world must be respected and valued.

In the classroom, teachers should encourage students to learn and have respect for diverse cultures because every culture has its values and uniqueness. And this could help to motivate students to develop critical thinking skills, build global awareness and engage in positive solutions for a sustainable future. Diversity presents a unique challenge for teachers, especially in the areas of assessment, instruction and socialization. Therefore, differences in culture and languages must be considered when administering and interpreting assessment or selecting instructional strategies and social activities in the school system for academic excellence. Teachers should be aware that students in the classrooms come from different background and as such have different 
learning styles and different learning abilities. Therefore, teachers should be patient in order to carry all the students along during teachinglearning processes. By understanding students learning styles, teachers could become more aware of how they teach. Moreover, being more reflective and aware of how students learn can improve learning and increase the teacher effectiveness for diverse learning. Teachers should be aware that their students may have learning preferences and develop learning plans and deliver instruction in a way that actively engages a variety of different learning styles or preferences. Examples include: learning by doing (Kinesthetic learning), taking time to explain concepts clearly (auditory learning) and using charts or handouts (visual learning). A teacher's understanding of his/her students may process information differently or may have different strategies for solving problems, will allow classroom instruction to more effectively meet the needs of all the students. By becoming sensitive to the diversity in learning represented among students, teachers can be more effective in generating positive educational outcomes for all students. Furthermore, acceptance of diversity among students in the classroom could promote students' involvement, engagement and better relationships among students with special needs and varying races and ethnicities. Also increased tolerance and acceptance of diversity in the classroom could help to improve academic outcomes of students. Teachers are encouraged to understand more about their students' strengths and abilities. However, focusing on what students' know requires learning more about their cultures and the experiences that they bring into the classrooms. Teachers' can use this knowledge of students' background, interest and experiences to develop culturally relevant pedagogy. Culturally relevant pedagogy is an effective instructional practice and theoretical model that promotes student achievement, supports students' cultural identity, and helps students to develop critical perspectives needed to challenge inequities in schools and society (Marmion, 2009).

\section{Gender Inequality in Nigeria}

Gender division or inequality permeates all aspects of Nigerian life. This inequality manifest in the family institution, educational sector, labor market, politics and social service institution. Ali, Adekeye and Raheem (2011) stated that girls' and women in some traditional
Nigerian societies are denied the simple rights to existence in the minds of their fathers who are the family heads. Ali et al emphasized that in some Nigerian communities, girls are considered to be transitory members of their families because the ultimate aim of the parents is to marry them out obligatorily into other families. As a result, the male family members take the advantage of the transient nature of girls in their birth homes to buttress the idea and feel that girls are of no value to their birth families.

In the educational sector, inequality between men and women is obvious. Discrimination against women in education is a common practice in many parts of Nigeria. Many of those who attempt to go to school are usually given out for marriages sometimes before the end of their primary education, while their male counterparts may continue to attain higher levels of education (Ali, et al, 2011). To confirm the above fact, Kelly (2013) stated that in the labor force, men constitute the bulk of the industrial workforce, while females constitute little percent of the total labor force in Nigeria and are mostly found in small scale enterprises including petty trading and food production.

In governance, the problems of gender divisions are equally obvious. An examination of the political system in Nigeria shows great disparities in favor of men. Many reasons abound for low females' participation in active politics. Females who try to succeed in politics face a lot of hurdles and difficulties. The natural physiological and biological differences between the genders as well as religious beliefs have greatly hindered the effective participation of females in politics (Omede, 2002).

\section{Improving Gender Equality through Sustainable Development}

In the past decade, there have been unprecedented socio-political commitments to sustainable development policies in national and international domains. The World Summit on Sustainable Development (WSSD) in Johannesburg, South Africa in (2002) marked a significant turning point in the world's effort towards the goal of sustainable development. Sustainable development at the local levels is believed to hinge upon improving the quality of life of the local populace with a transition towards meeting their basic needs, reducing hunger and poverty (Chinweze, Abiloa-Oloke and Jideani, 2009). The summit brought to the force the need to involve women in achieving this objective 
through active participation in the economy, politics and the overall economic growth. UNESCO (2005) stated that education is a precondition for sustainable development, economic growth and poverty reduction. As such, UNESCO emphasized that education is a fundamental human right and the most powerful lever for the promotion of welfare, civic and social advancement of every country. UNESCO through education for sustainable development works to promote equal opportunities to quality learning, free from gender- based or other forms of discrimination. Therefore, the adoption and implementation of recommended policy measures could go a long way in improving gender relation in the Nigerian society thereby enhancing the task of national development in the 21st century and achievement of the Millennium Development Goals (MDGs), now sustainable development Goals for sustainable future. Government at all levels in cooperative partnership with other stakeholders in Nigeria has to step up efforts so that appreciable progress could be achieved in a developmental fashion. The sundry organs, institutions and agencies of government should as a matter of exigency, be strengthened for policy efficiency and accelerated sectorial performance.

\section{Implications for Educational Sustainability on National Development}

Education for sustainability cannot be achieved without quality education of its citizenry which is free from all forms of discrimination. This study had interesting implications.

- Education would be used as a tool to achieve sustainability in the use of Energy, water/ land and also the abuse of human right shall be reduced.

- Peace, justice, national development and democracy could be attained through Education for sustainability.

- Poverty and disparity reduction would also be attained through Education at least to barest minimum.

- Educating women creates more equitable lives for women and their families and increases their ability to participate in community decision making and work towards achieving local sustainability goals.

- Women and children education are required for increased productivity.
- If citizens are educated by the year 2020, the literacy rate and skilled workforce will be enhanced.

- Education improves quality of life, raises the economic status of families, lowers infant mortality and improves the educational attainment for the next generation, thereby raising the next generation's chances for economic and social wellbeing.

- Education for sustainability could provide learners with the knowledge, dispositions, skills and values that will motivate and empower them to become active citizens and take measures to live more sustainably.

- Education for sustainability incorporates key environmental challenges like climate change into core subjects like Mathematics, Science and Arts and also involves modifying the teaching- learning process to a more all- encompassing approach.

\section{Suggestions for Way Forward}

The following suggestions are made by the researchers based on this review and implications of this study.

1. The Department of Education and Skills should provide a specific Education for Sustainable Development (ESD) portal on its website. This portal should make the findings of ESD research available through the proposed ESD web portal and consider the issues that arise from the findings of such research.

2. The Department on Education for sustainable Development and National Council for Curriculum and Assessment (NCCA) should ensure that ESD principles are integrated into all relevant primary and post primary curriculum areas as the curriculum is reviewed.

3. Education Sector Support Program in Nigeria (ESSPIN) should support the Federal and the State Government in Nigeria to make sustainable improvements in basic education services and reforms. With their support, education could be transformed by the year 2020. The program should support the government, teachers and the communities to create the enabling conditions in which an effective learning 
environment can be nurtured. This program should also support the government in policy making, monitoring and evaluating education services in Nigeria.

4. The Department of Education and Skills and (NCCA) should ensure that the voice of students is taken into consideration where new curricular and specifications are being developed.

\section{REFERENCES}

Ali, A. A., Adekeye, S. D and Raheem, A. S., 2011. Towards Improving Gender Relations in Nigeria: Implication for Sustainable Development. University of Ilorin, Nigeria. Journal of Sustainable Development in Africa. 13, (8): www.jsd africa.com/jsda/vol13no8winter.

Carla., 2014. What is culture?. Centre for Advanced Research on Language Acquisition. University of Minnesota.www.Carla.umn.edu/culture/d efinitions.html.

Chinweze, C., Abiola-Oloke, G and Jideani, C., 2009. "Energy Resources Management for Development in Nigeria Niger Delta Region. Women Issues and the Environment". World Academy of Science, Engineering and Technology 54: 1167-1169.

Department of Education and Skills., 2007. Discussion paper: National Strategy on Education for Sustainable Development in Ireland. AnRoinn Department of Oideachais Education AgusScileannaand skills.

Dictionary.reference.com/browse/academic.Retri eved $21^{\text {st }}$ August, 2015.

Editors of Enclopedia Britanica., 2014. www.britanica.com/topic/academicfreedom.

Ejikeme, P. O., 2014. Education for Sustainable Development. IOSR Journal of Research \& Method in Education. (IOSR - JRME), 4, (3): $12-15$.
Fourie, I., 2008. Academic Freedom Manual $7^{\text {th }}$ ed. Collection building 27 (2) Emenald group publishing Itd.

Gollnick, D. M and Chinn, P. C., 2006. Multicultural Education in a pluralist Society $\left(7^{\text {th }}\right.$. ed $)$. Upper Saddle River, NJ: Pearson

http:www.Sustainable Development 2015.org

Kelly, B. O., 2013. Gender Equality and Women Empowerment in Nigeria. The Desirability and Inevitability of Pragmatic Approach. A celebration ofwomen.org/2013/05/gender.

Nayar, A., 2013. Importance of Education for Sustainable Development. http://wwf.panda.org/?210950/importanc e for sustainable......

Nicole, P. T and Miles, A. I., 2010. Cultural and Linguistic Diversity: Issues in Education Kendall Hunt Publishing. "Special Education for all Teachers," $5^{\text {th }}$ ed. Co.www.kendalhunt.com/colarusso. Retrived $23^{\text {rd }}$ March,2015.

Omende, A. J., 2002. "Strategies for the Political Empowerment of Women in Nigeria 1999 and Beyond". Alore- Ilorin. Journal of Humanities', 12.

Osuuyikanmi, A. F., 2000 "Globalization and the Deepening of Gender Imbalance in Nigeria". Journal of Policy Initiative 3, (2):

The United Millennium Declaration., 2000. www.org/millennium/declaration/areas55 2e.htm,8/9/2000.

Tylor, E., 2012. ocw.mit.edu/courses/anthropolog y/219-01-how-culyure-works-fall2012/readings/MIT21A-01f12-sir Edwardcul.pdf.

UNESCO., 2005-2014. The UN Decade of Education for Sustainable Development. www.journalsbank.com/ejg dr 9 4pdf. Universal Declaration of Human Rights UN Retrieved 2010.

UNESCO and UNEP., 2002. Cultural Diversity and Biodiversity for Sustainable 
Development. Johannesburg, Nairobi Kenya.www.unep.org.

UNESO., 2005 "Education and Culture in Africa. Quest for Development $6^{\text {th }}$ ordinary session of the Assembly of Heads of State and of Government of the African union. UNESCO Preliminary contribution.

UNESCO., 2013. The UN Decade of Education for Sustainable Development in Bonn, Germany.http://unesdoc.unesco.org/imag e/0014/001403/14037 2e.pdf. Retrieved $25^{\text {th }}$ Sept. 2015.
Universal Declaration of Human Rights UN Retrieved 2010. www.journalsbank.com/ejgdr-9- 4.pdf.

Zimmermann, K. A., 2015. Live Science contributor, what is Culture? http://m.livescience.com/21473-what-isculture.

Retrieved

Feb.www.britanica.com/...../acafreacademicfree2014 